\title{
Mulher, Saúde e Trabalho no Brasil: Desafios para um Novo Agir
}

\author{
Women, Health, and Labor in Brazil: Challenges for New Action
}

\author{
Estela Maria L. de Aquino ${ }^{1}$ \\ Greice Maria de S. Menezes ${ }^{1}$ \\ Lilian Fatima B. Marinho'
}

\section{AQUINO, E. M. L; MENEZES, G. M. S. \& MARINHO, L. F. B. Women, Health and Labor in Brazil: Challenges for New Action. Cad. Saúde Públ., Rio de Janeiro, 11 (2): 281-290, Apr/Jun, 1995.}

Despite the remarkable rise in women's participation in the labor market in Brazil, its consequences on health are still virtually unknown. This study aims to identify theoretical and methodological problems in the relationship between labor and women's health from a gender perspective. Characteristics of women's occupational placement are described and analyzed as resulting from their role in social reproduction. The study examines the development of several conciliatory strategies between paid work and housework which are discussed as potential determinants of health problems and support the need for a critical reappraisal of theoretical and methodological strategies to reach a better understanding of the complexity and specificities of women's living and working conditions. The author also stresses the role of women's recent participation in the trade union movements in defense of health, body rights, and women's issues in the workplace, as well as the need for a new framework embodied in the women's social movement. The study thus points to the challenge to produce knowledge on this subject in order to unveil the uniqueness of the national scenario marked by unemployment, informal jobs, low salaries, weak trade unions and other civil organizations, and traditional domestic and marriage relationships.

Key words: Women's Health; Occupational Health; Gender; Social Movement

\section{INTRODUÇÃO}

No início da década de 80, em um encontro internacional sobre saúde ocupacional da mulher, trabalhadoras e pesquisadoras presentes constataram que nos dezesseis países de seis continentes de onde elas vinham, a situação das mulheres trabalhadoras era muito parecida, estando estas restritas a poucas ocupações e expostas a precárias condições de trabalho (Messing, 1992). Apesar disso, surpreendentemente, persistia um desconhecimento generalizado sobre os efeitos do trabalho feminino sobre a sua saúde.

\footnotetext{
${ }^{\prime}$ Núcleo de Estudos Mulher e Saúde, Universidade Federal da Bahia. Rua Padre Feijó, 29, 4a andar, Anexo II, Salvador, BA, 40110-170, Brasil.
}

Esse desconhecimento, certamente decorria, em primeiro lugar, da invisibilidade das atividades laborais das mulheres, já que até bem recentemente o conceito de trabalho estava restrito às atividades produtivas desenvolvidas nas indústrias, majoritariamente por homens. Conseqüentemente, sendo as atividades das mulheres "inexistentes", não poderiam ter efeitos sobre sua saúde. Um exemplo marcante dessa invisibilidade relaciona-se ao trabalho noturno hospitalar, exercido preponderantemente por mulheres. Apesar de ser uma das formas mais antigas dessa modalidade de organização do trabalho e de dificilmente poder ser abolido pelas características de continuidade da assistência em saúde, quase todo o conhecimento existente sobre sua relação com a saúde de quem o exerce foi produzido a 
partir do estudo de populações masculinas, particularmente trabalhadores industriais (Carpentier \& Camazian, 1977; OIT, 1990; Rutenfranz et al., 1989).

Em segundo lugar, o fato de a mulher ser vista, na medicina moderna, essencialmente como mãe (Donzelot, 1980; Krieger \& Fee, 1994; Nunes, 1991), orientou quase toda a produção científica para os aspectos reprodutivos da saúde, privilegiando-se aqueles relativos à saúde do feto (Lewin \& Olesen, 1985).

Como resultado da combinação desses dois fenômenos, a quase totalidade dos estudos sobre saúde ocupacional concentrava-se em setores da economia onde a participação feminina era inexpressiva (Dumais, 1992) e, na maioria das vezes, as mulheres eram excluídas, sob alegação de que seu pequeno número tornaria os achados inconclusivos. Os estudos sobre a mulher trabalhadora restringiam-se aos efeitos nocivos do trabalho na reprodução, orientando toda a legislação de proteção à mulher que era vista sempre como potencialmente grávida.

Ainda em anos recentes, a produção científica sobre os efeitos do trabalho sobre a saúde das mulheres persiste minoritária. Em pesquisa bibliográfica envolvendo todos os artigos indexados em saúde ocupacional, publicados de 1986 a 1993 , apenas $27,4 \%$ mencionavam as palavras women ou female em qualquer dos seus campos, inclusive o resumo (Rattner, 1993).

No Brasil, em particular, a situação é ainda pior e a produção científica sobre o tema é muito fragmentada e dispersa. A influência da produção teórica feminista, particularmente as contribuições advindas das Ciências Sociais, é incipiente na área de saúde e, apesar da variável sexo ser incluída na maioria dos estudos, as diferenças entre homens e mulheres tendem a ser naturalizadas. Em contrapartida, o saber produzido em saúde permanece encistado, sem alimentar o debate sobre o tema em outras áreas do conhecimento científico e dos movimentos sociais organizados.

Este texto busca situar o problema e levantar questões de modo a contribuir para a discussão sobre os desafios de curto e médio prazos na definição de políticas voltadas para a melhoria das condições de trabalho e de saúde das mulheres.

\section{MULHER E TRABALHO NO BRASIL}

As mulheres estiveram presentes no mercado de trabalho desde o início da industrialização no país. Todavia, essa participação caracterizou-se por períodos de fluxo e refluxo condicionados pelas necessidades do capital (Pena, 1981). Até muito recentemente o trabalho das mulheres teve, em relação ao dos homens, um caráter complementar na sustentação da família, fazendo com que sua inserção fosse intermitente, em atividades de baixa qualificação e com conseqüente baixa remuneração.

Nos últimos vinte anos, contudo, registrou-se uma acelerada e crescente incorporação das mulheres no mercado de trabalho. Entre 1976 e 1985, a taxa de atividade feminina passou de $28,7 \%$ para $36,9 \%$, com um crescimento do contingente de mulheres economicamente ativas a uma taxa geométrica anual de 5,6\%, contra apenas 2,9\% de incremento do contingente masculino (Médici, 1989). Segundo Hirata apud Castro (1990), enquanto a taxa de atividade masculina vem apresentando variações que incluem o crescimento de 78 a 81 e a diminuição de 81 a 84 , as taxas de atividade feminina vêm crescendo mesmo com a crise, em cujo ápice, abriram-se para as mulheres oportunidades de trabalho no mercado formal (Castro, 1990).

Em um primeiro momento, parte desse crescimento poderia ser explicada como decorrência de mudanças metodológicas introduzidas nos censos e nas Pesquisas Nacionais por Amostra de Domicílios (de realização anual) por influência de pesquisadores/as feministas (Aguiar apud Nash, 1985), que modificaram o processo de coleta de dados sobre o trabalho, conferindo maior visibilidade às atividades das mulheres. Todavia, essa tendência ao aumento da participação feminina tem se acentuado e é consistente com o que vem ocorrendo em outros países da América Latina (Nash, 1985; Safa, 1987).

Ainda que a maior parte dos estudos enfatize a primazia de determinantes econômicos como a crise, o empobrecimento da população e a conseqüente degradação das condições de vida (Bruschini apud Lavinas \& Castro, 1990; Safa apud Lavinas \& Castro, 1990; Safiotti apud Lavinas \& Castro, 1990), uma hipótese bastante 
plausível é a de que, além disso, estariam ocorrendo mudanças nos valores relativos ao trabalho feminino, o que conferiria ao fenômeno um atributo de irreversibilidade (Hirata apud Lavinas \& Castro, 1990).

Apesar disso, a inserção feminina continua se dando em menores proporções e de modo bastante diferenciado da masculina. $\mathrm{O}$ processo de terciarização da economia brasileira, caracterizado pelo subemprego em atividades de baixa produtividade, baixo prestígio e baixa remuneração, atingiu primordialmente a força de trabalho feminina (Barroso, 1982).

De qualquer modo, essa distinção faz com que a inserção masculina e feminina no mercado de trabalho seja vista e interpretada de formas diferentes, sendo o trabalho do homem considerado fundamental e o trabalho da mulher complementar. Estabelece-se aí a segregação ocupacional, característica universal do trabalho feminino (Bruschini \& Rosemberg, 1982), pela qual a grande maioria das mulheres que tem trabalho remunerado está sujeita a se concentrar em poucas ocupações, principalmente nas atividades informais, no serviço doméstico, como trabalhadoras rurais e como externas de fábricas (Nash, 1985; Safa, 1987).

Em 1985, os setores da economia que absorveram com mais intensidade o trabalho feminino foram a prestação de serviços $(32,1 \%)$, o setor social $(17,1 \%)$, o setor agrícola $(18,47 \%)$, a indústria de transformação $(11,6 \%)$ e o comércio de mercadorias $(10,4 \%)$, sendo os dois primeiros caracterizados pela absoluta preponderância de mulheres (Médici, 1989).

No setor de prestação de serviços, cuja maioria dos empregos corresponde ao serviço doméstico, as mulheres eram, naquele mesmo ano, $65 \%$ das pessoas ocupadas. Nas atividades sociais, caracterizadas em sua maior parte por ocupações da saúde e da educação, a participação feminina de $73 \%$ era incontestavelmente hegemônica (Médici, 1989).

A atividade feminina tem sido marcada por um refluxo durante o período de maior cuidado e educação dos filhos. Entre as que permanecem empregadas, um alto percentual trabalha em "tempo parcial" (Médici, 1989). Isso porque a incorporação crescente de novas atividades fora do lar não as têm necessariamente desobrigado das antigas funções. Sem equipamentos sociais que as liberem ou aliviem das tarefas domésticas e dos cuidados com os filhos, grande número de mulheres é levado a optar por jornadas parciais e até mesmo por interrupções freqüentes na vida profissional. Contudo, amplos contingentes de mulheres são pressionados a trabalhar em horário integral, por razões financeiras, nem por isso ficando isentas da dupla jornada de trabalho (Barroso, 1982), a qual tem se generalizado nos setores populares (Bruschini apud Lavinas \& Castro, 1990; Machado apud Lavinas \& Castro, 1990; Safiotti apud Lavinas \& Castro, 1990).

A influência do papel da mulher na reprodução social é tão grande, que a própria escolha e a manutenção do emprego, da extensão das jornadas e dos turnos de trabalho profissional incluem entre os critérios a possibilidade de conciliação com o cuidado da casa e dos filhos. Estudos realizados em várias partes do mundo, inclusive em nossa realidade (Machado-Neto, 1987; Volkova \& Bar apud Machado-Neto, 1987), revelam que a proximidade entre a casa e o local de trabalho é um dos critérios fundamentais de escolha do emprego, mesmo em detrimento de outros como o salário e a satisfação profissional. Muitas mulheres optam, quando é possível, por jornadas parciais, mesmo com prejuízos salariais e de progressão funcional, para poderem se dedicar mais aos filhos pequenos.

Por isso mesmo, Lavinas \& Castro (1990) chamam a atenção para a importância assumida pelo ciclo de vida na compreensão do trabalho exercido pelas mulheres. No estudo desta temática, seria portanto indispensável a utilização de variáveis como a idade, a situação conjugal e a posição na família, o número e a idade dos filhos.

Contudo, o contínuo crescimento da entrada de esposas no mercado formal de trabalho (Bruschini apud Lavinas \& Castro, 1990; Castro apud Lavinas \& Castro, 1990; Spindel apud Lavinas \& Castro, 1990) estaria implicando a progressiva inadequação desse instrumental teórico. Para Hirata apud Lavinas \& Castro (1990) seriam as relações homem-mulher no interior do casal e a relação salarial que estariam conformando efetivamente a relação mulher-trabalho. 
Da mesma forma, Spindel apud Lavinas \& Castro (1990) contesta a primazia do ciclo de vida da família, defendendo que a inserção da mulher no mercado de trabalho depende do que representa o salário - se complementar, em relações de trabalho mais flexíveis; se indispensável, em empregos com relações de trabalho mais definidas.

Há que se considerar ainda, um fenômeno relativamente recente caracterizado pelo aumento marcante de mulheres chefes de família (Valdes \& Gomariz, 1993), que corresponderam, em 1989, a 20,1\% do total de famílias, representando hoje uma parcela considerável do universo de mulheres que trabalham (IBGE, 1992). Longe de expressar um avanço pelas modificações do papel da mulher no interior da família, as mulheres chefes de família são as mais pobres entre as pobres, sendo as maiores proporções encontradas na região Norte do país (Valdes \& Gomariz, 1993).

Um outro traço fundamental da situação da mulher, na conjuntura dos últimos vinte anos, que possivelmente também contribui para a saída das mulheres do espaço restrito em que se encontravam, relaciona-se à brutal queda da fecundidade que, já na década de 70, foi da ordem de 24,5\%, chegando-se em 1980 à média de 4,3 filhos por mulher (Radis/Dados, 1986). Essa tendência acentuou-se nos anos 80, reduzindo para cerca de 3 o número médio de filhos encontrado no Censo de 1991, o que implicou, inclusive, um impacto demográfico superior ao esperado (Diegues \& Tolipan, 1992; Tolipan, 1992). Às necessidades concretas certamente se aliam ao maior interesse das mulheres em controlar a reprodução e a maior disponibilidade de métodos contraceptivos no Brasil, o que tem se expressado em altos percentuais de utilização dos mesmos (Simões \& Oliveira, 1988). Cabe salientar o caráter irreversível do fenômeno, já que decorre principalmente da esterilização de um amplo contingente de mulheres jovens, chegando a representar, respectivamente no Maranhão e em Goiás, 79,8\% e 74,7\% do total de mulheres em uso de métodos contraceptivos (Berquó, 1989; Costa \& Pinto, 1989).

\section{TRABALHO E SAÚDE DAS MULHERES}

Com a entrada progressiva das mulheres no mercado de trabalho, nos países industrializados centrais, o predomínio quase exclusivo de estudos concentrados em indivíduos do sexo masculino vem sendo modificado. Começaram a surgir estudos sobre os efeitos do trabalho na saúde de populações femininas, principalmente explorando diferenças quanto à prevalência de sintomas e de doenças entre trabalhadoras e donas de casa (Waldron, 1983). Entretanto, deve ser aceita com cautela a constatação de um possível efeito benéfico do trabalho profissional sobre a saúde das mulheres, demonstrada por diversas autoras (Lã Rosa, 1988; Nathanson, 1977; Sorensen \& Verbrugge, 1987; Waldron, 1983; Wingard, 1984). Em primeiro lugar, porque envolve um fenômeno bastante descrito em estudos sobre populações masculinas - o efeito do trabalhador sadio -, pelo qual pessoas sadias teriam maior probabilidade de conseguir e manter uma inserção no mercado de trabalho formal (Meijers et al., 1989). Além disso, mulheres donas de casa e trabalhadoras constituiriam grupos "selecionados" de modo diverso quanto às próprias condições familiares, inclusive quanto ao apoio efetivo, seja de outras mulheres (empregada, mãe, sogra, etc.) e/ou do próprio marido ou companheiro, no desenvolvimento das tarefas de cuidados da casa e dos filhos. A comparabilidade de tais grupos, portanto, deveria levar em conta essas dimensões para não se correr o risco de chegar a conclusões falaciosas quanto aos perfis de adoecimento em cada um deles.

As ocupações tradicionalmente exercidas por mulheres têm sido negligenciadas como objeto de estudo quanto aos efeitos sobre a saúde. É fato conhecido que o trabalho agrícola, por ser diretamente associado ao trabalho familiar, não é reconhecido como tal, inclusive pelas próprias trabalhadoras que o identificam como "uma ajuda" ou "um trabalhinho à toa" (Lavinas \& Castro, 1990). Todavia, tanto quanto os trabalhadores homens, as trabalhadoras rurais estão expostas a um conjunto de agravos à saúde como, por exemplo, os agrotóxicos e outras substâncias químicas de uso indiscriminado que, sabidamente, provocam intoxicações agudas (mui- 
tas vezes letais), além de estarem relacionados à ocorrência de abortamentos e malformações fetais e ao desenvolvimento de leucemias e tumores de fígado e de pele (MS/SNAS/ Inca/ Pro-Onco, 1993). Outros exemplos comuns aos homens e às mulheres envolvem a exposição continuada ao sol, associada ao câncer de pele e ao envelhecimento precoce; as posturas antiergonômicas levando a problemas osteomusculares; e as mutilações por instrumentos cortantes de trabalho.

O trabalho em saúde, exercido majoritariamente pelo pessoal de enfermagem (Machado, 1989), tem forte conteúdo relacional, no cuidado de outras pessoas, em situações de dor e de sofrimento, envolvendo especificidades que se ajustam perfeitamente bem às qualidades de destreza, paciência, interesse em ser útil e dedicação, características "tipicamente femininas" em nossa e em outras sociedades. A persistência de uma visão idealizada da profissão se contrapõe à excessiva carga de atividades que envolve o trabalho por turnos e noturno, que sabidamente ocasiona problemas digestivos, distúrbios do sono e mentais, além de repercussões sobre a vida familiar e social (Rutenfranz et al., 1989). No caso das mulheres, indaga-se não só os impactos específicos sobre o ciclo reprodutivo e menstrual. Adicionalmente, a exposição a fatores de risco mecânicos e ambientais específicos é, ainda, agravada pelos recursos materiais insuficientes e inadequados, que ocasionam condições inseguras no trabalho (Alves, 1987; 1988). Os estudos sobre condições de saúde desse grupo ocupacional são razoavelmente freqüentes em outros países, citando-se, entre outros, Gray-Toft \& Anderson (1981); Morgan \& Davis (1989); Owen (1989); Parkes (1980); Thierney et al. (1990); Topf (1988); Triolo (1989a, 1989b). No Brasil, todavia, são raros e inespecíficos (Pitta, 1991; Posso, 1988; Valtorta et al., 1985); os existentes, em geral, referem-se aos riscos potenciais de insalubridade ou ao absenteísmo por motivos de saúde do pessoal que trabalha em hospitais.

Em outras ocupações, é imperioso estimar a magnitude de problemas, sabidamente relacionados ao trabalho, como as queixas de varizes, infecções urinárias, problemas de coluna e distúrbios psico-emocionais, em bancárias e co- merciárias; ou as alergias respiratórias e dermatológicas, calos nas cordas vocais e distúrbios da voz, em professoras. Dessa forma, será possível a proposição de medidas de proteção à saúde das trabalhadoras.

$\mathrm{O}$ aumento da participação de mulheres em ocupações anteriormente restritas a trabalhadores do sexo masculino, como nas indústrias dinâmicas (especialmente a metalúrgica e a metal-mecânica), além do crescimento de oportunidades de trabalho do tipo "colarinho branco" para mulheres da classe média, têm colocado a necessidade de estudos epidemiológicos que atualizem, dentro de uma perspectiva de gênero, o conhecimento produzido exclusivamente a partir da observação de grupos de homens. Também são necessários estudos ergonômicos, a fim de redimensionar e adequar os equipamentos às medidas antropométricas femininas, de modo a reduzir o desgaste e a fadiga. A inadequação de equipamentos e de mobiliário está presente mesmo em espaços onde as mulheres são maioria, como em ambientes hospitalares (Estryn-Behar \& Poinsignon, 1989), pois as medidas - pretensamente universais - tomam como referência o homem, resultando em posturas antiergonômicas e em cansaço muscular para as trabalhadoras.

O surgimento de novos postos e processos de trabalho, como a informática e o recente processo de automação industrial, vem sendo estudado com crescente interesse, não só do ponto de vista do comprometimento físico dos trabalhadores, com as lesões por esforço repetitivo (LER), como também pelos distúrbios psico-emocionais decorrentes de um sofrimento mental gerado pelo trabalho. Como as mulheres constituem grande parte dessa força de trabalho, principalmente nas tarefas de menor qualificação, passam a ser estudadas, ainda que, de um modo geral, não exista um enfoque especial que contemple as especificidades do trabalho feminino. Assim, como resultado de rara exceção, sabe-se que a síndrome de LER, freqüente principalmente em digitadoras, causa progressiva e grave limitação das atividades profissionais, mas também tem sérias repercussões sobre as demais atividades cotidianas, entre elas as tarefas domésticas (Aquino, 1992).

Por isso, não se trata apenas de incorporar as mulheres aos estudos, escolhendo-se grupos 
ocupacionais que as concentrem e aplicando os mesmos modelos teóricos desenvolvidos, anteriormente, na investigação de populações masculinas. Há que se repensar criticamente teorias e conceitos, estratégias metodológicas, fontes de informação, de modo a dar conta da complexidade e das especificidades das condições de trabalho e de existência das mulheres.

A questão da violência no trabalho, por exemplo, não pode ser tratada da mesma forma que para os homens. As relações de dominação patriarcal se reproduzem em todas as esferas da vida, inclusive no trabalho. Além das relações de opressão comuns a todos os trabalhadores, as mulheres sofrem vários tipos de violências específicas como o assédio sexual, tão freqüente entre as secretárias e as empregadas domésticas; os constrangimentos de controle da reprodução, como a prática de vistoria de absorventes comprovando a menstruação; testes de gravidez nos exames admissionais e periódicos, além das famosas revistas nas saídas de fábricas, que utilizam a sexualidade feminina na criação de mecanismos de controle social das trabalhadoras.

Um outro aspecto que possivelmente revela diferenças entre homens e mulheres diz respeito ao próprio sofrimento mental gerado pelo trabalho. No dizer de Elizabeth Souza-Lobo (1991: 188), “(...) a assimetria nas relações de trabalho masculinas e femininas se manifesta não apenas na divisão de tarefas, mas nos critérios que definem a qualificação das tarefas, nos salários, na disciplina de trabalho". As mulheres são socializadas desde a mais tenra infância para o seu papel na reprodução social e esse processo de qualificação será mais tarde extremamente conveniente para o capital. A docilidade, a paciência, a resistência para o trabalho monótono e repetitivo são qualidades pretensamente naturais das mulheres, que resultam, na verdade, desse longo processo de qualificação para o trabalho (Kergoat, 1990). É provável então que a relação das mulheres com o trabalho como fonte de sofrimento e também de prazer seja profundamente marcada por esse processo de socialização.

Entretanto, a mesma divisão sexual do trabalho que mantém as mulheres concentradas, ainda hoje, em poucas ocupações, consideradas tipicamente femininas, faz com que cai- bam quase exclusivamente a elas as atribuições de cuidado da casa e dos filhos. Assim, os novos fatores de risco inerentes ao trabalho profissional somam-se aos antigos decorrentes do trabalho doméstico, podendo, inclusive, se potencializar. Isso significa, portanto, que os estudos sobre a relação entre saúde e trabalho de mulheres devem contemplar ambas as esferas.

Da mesma forma, o estudo do desgaste físico no trabalho não pode se restringir ao trabalho profissional, porque ao contrário da maioria dos homens que ao chegar a casa, mesmo que por poucas horas, terá espaço para o descanso e o sono, as mulheres enfrentam uma outra jornada, muitas vezes mais penosa e mais desgastante. Mulheres comerciárias ou bancárias, por exemplo, cujas atividades profissionais não envolvem grande esforço físico, podem em sua segunda jornada realizar tarefas pesadas como faxinas, lavagem de roupas e cuidados de crianças pequenas, que implicam muitas vezes fadiga crônica, não explicável pelo esforço profissional. Por outro lado, com extensas jornadas semanais, é mínimo o tempo que sobra para a reposição do desgaste, com horas de sono, o lazer, a alimentação e outros cuidados com o corpo.

Mas não se trata apenas da conjugação de fatores de risco em ambas as esferas. O próprio esforço de conciliação dos dois trabalhos gera ansiedades e tensões cujas implicações sobre a saúde física e mental das mulheres são ainda mal conhecidas e precisam ser estudadas.

\section{CONSIDERAÇÕES FINAIS}

A investigação sobre o tema mulher, trabalho e saúde requer um percurso transdisciplinar, obrigando a intensificação de um diálogo ainda incipiente entre a sociologia do trabalho e a saúde ocupacional.

Isto porque, de um lado, a sociologia do trabalho tomava, até bem recentemente, o lugar na produção como um elemento unificador, ignorando outras categorias como idade, raça e particularmente gênero. As referências às mulheres trabalhadoras recorriam a estereótipos e as comparações estabelecidas entre homens e mulheres do mundo do trabalho objetivavam 
revelar especificidades e particularidades dessas últimas, tomando sempre como referência o homem como modelo pretensamente universal (Kergoat, 1978).

Por outro lado, como assinalado anteriormente, a saúde ocupacional vem privilegiando a análise das mulheres do ponto de vista de sua função na reprodução. O trabalho feminino tem sido alvo de preocupações acerca dos seus possíveis impactos na saúde do feto, desconhecendo-se a integralidade de seres humanos sexuados na sua complexa relação com o trabalho.

Ao destruir a unanimidade dos conceitos aplicados até então ao conjunto da classe trabalhadora, as reflexões feministas têm fomentado a construção de novos instrumentos teórico-metodológicos, possibilitando um novo olhar sobre a realidade, que ao colocar diferentemente as questões, têm permitido, assim, o encontro de respostas igualmente diferentes.

As mulheres são mais frágeis nos enfrentamentos capital-trabalho, o que as torna menos visíveis e ouvidas como sujeitos de protesto. É uma constante a referência às baixas taxas de sindicalização das mulheres que, em 1986, representavam apenas $14,4 \%$ das mulheres ocupadas de 18 anos e mais (Castro, 1990). Esse traço tem sido apontado como uma qualidade por uma parcela do empresariado, que justifica sua preferência pela contratação de mulheres, pela sua maior docilidade e submissão (Castro, 1990). Isso se agrava, na medida em que mesmo aquelas sindicalizadas enfrentam restrições à sua participação política por parte dos maridos, dos companheiros de trabalho e de sindicato, sendo tratadas no próprio movimento sindical a partir de estereótipos da mulher. A maioria dos sindicalistas homens continua a perceber com estranheza as mulheres e seus comportamentos, entendendo suas reivindicações como específicas de um subgrupo detentor de certas particularidades (Kergoat, 1978).

Dessa forma, as questões relacionadas aos efeitos do trabalho sobre a saúde das mulheres trabalhadoras mal começam a ser colocadas em pauta numa perspectiva que supere a sua função única e exclusiva de procriadora. Todavia, é possível detectar uma recente atuação das mulheres sindicalistas que buscam superar as lutas exclusivamente econômicas, na defesa do direito ao corpo, à saúde e à feminilidade no ambiente de trabalho (Delgado \& Lopes, 1992). Essa influência de qualidade nova pretende incorporar a dimensão de gênero às análises sobre saúde e condições de trabalho, transformando o espaço sindical em lugar de homens e de mulheres. O desafio de se gestar esse novo agir não pode prescindir de um novo olhar, que se produz de modo ainda incipiente no espaço acadêmico, por inspiração do movimento social de mulheres.

No Brasil, hoje, é praticamente impossível traçar um quadro da saúde da mulher trabalhadora, o que faz com que conferir visibilidade aos fenômenos ainda seja uma questão primeira. Os dados oficiais, apontados como insuficientes para o estudo do conjunto da população trabalhadora (entenda-se trabalhadores masculinos), são completamente inexplorados quanto às diferenças entre homens e mulheres, sendo, portanto, a questão da qualidade e da adequação dos mesmos completamente imponderável. É recomendável, portanto, que os dados sejam utilizados, no sentido de criticá-los e aperfeiçoá-los.

Mas isso só não basta. É necessário que sejam estimulados e apoiados novos estudos que preencham lacunas e antecipem questões, tanto no que diz respeito ao dimensionamento da magnitude dos problemas de saúde associados às ocupações tradicionais, quanto na investigação de fenômenos ainda desconhecidos relacionados aos novos postos e novas formas de organização do trabalho.

Mais do que isso, é imperioso desvendar as singularidades decorrentes das condições em que se processam as relações de trabalho no Brasil. O conhecimento já produzido nos países centrais deve, portanto, ser repensado e retraduzido, de modo a inspirar novas hipóteses que contemplem as especificidades de uma realidade caracterizada pelo desemprego, o trabalho informal, os baixos salários, a fragilidade das organizações sindicais e sociais, além de relações tradicionais familiares e matrimoniais, onde cabe às mulheres a responsabilidade exclusiva de cuidado da casa e dos filhos. Nesse quadro, as imbricações do gênero com a classe, a raça, a geração, longe de ser uma abstração teórica, cons- 
tituem a experiência concreta de sujeitos em movimento: homens e mulheres lutando pela sobrevivência e contra a exclusão social.

\section{RESUMO}

AQUINO, E. M. L.; MENEZES, G. M. S. \& MARINHO, L. F. B. Mulher, Saúde e Trabalho no Brasil: Desafios para um Novo Agir. Cad. Saúde Públ., Rio de Janeiro, 11 (2): 281-290, abr/jun, 1995.

Apesar do marcante aumento da participação das mulheres no mercado de trabalho, no Brasil, persiste um desconhecimento generalizado sobre os efeitos do trabalho sobre sua saúde. Neste artigo, em revisão da literatura, pretendeu-se identificar questões teóricas e metodológicas na análise das relações entre trabalho e saúde de mulheres a partir de uma perspectiva de gênero. Assinala-se as características da inserção profissional feminina, decorrentes de seu papel na reprodução social, que resultam na necessidade de estratégias variadas de conciliação entre as atividades profissionais e as domésticas. Discute-se as implicações da inserção social das mulheres trabalhadoras para a sua saúde e a necessidade de repensar criticamente teorias e conceitos, estratégias metodológicas, fontes de informação, para dar conta da complexidade e das especificidades das condições de trabalho e de existência das mulheres. A recente atuação das mulheres sindicalistas na defesa do direito ao corpo, à saúde e à feminilidade no ambiente de trabalho não pode prescindir de um novo olhar, que se produz de modo ainda incipiente no espaço acadêmico, por inspiração do movimento social de mulheres. Nesse sentido, apontam-se os desafios para a produção do conhecimento sobre o tema, que desvendem as singularidades da realidade nacional, caracterizada pelo desemprego, o trabalho informal, os baixos salários, a fragilidade das organizações sindicais e sociais, além de relações tradicionais familiares e matrimoniais.

Palavras-Chave: Saúde da Mulher; Saúde Ocupacional; Gênero; Movimento Social

\section{REFERÊNCIAS BIBLIOGRÁFICAS}

ALVES, D. B., 1987. Mercado e Condições de Trabalho na Enfermagem. Salvador: Gráfica Central Ltda.

1988. Condições de Trabalho na

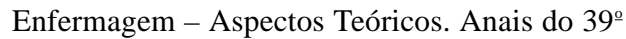
Congresso Brasileiro de Enfermagem, 23 a 27 de novembro de 1987, Salvador. (Mimeo.)

AQUINO, R., 1992. LER: Doença das Trabalhadoras. Tese de Mestrado, Salvador: Universidade Federal da Bahia.

BARROSO, C., 1982. Mulher, Sociedade e Estado no Brasil. São Paulo: Unicef/Brasiliense.

BERQUÓ, E., 1989. A Esterilização Feminina do Brasil Hoje. Quando a Paciente é Mulher. Brasília, DF: CNDM.

BRUSCHINI, M. C. A. \& ROSEMBERG, F., 1982. A mulher e o trabalho. In: Trabalhadoras do Brasil (M. C. A. Bruschini \& F. Rosemberg, orgs.), pp. 09-22, São Paulo, Brasiliense.

CARPENTIER, J. \& CAMAZIAN, P., 1977. El Trabajo Nocturno: sus Efectos Sobre la Salud y el Bien Estar del Trabajador. Ginebra: Organización Internacional del Trabajo.

CASTRO, M. G., 1990. Mulher e crise no Brasil: A mulher no mercado de trabalho urbano dos anos 80. Cadernos do CEAS, 129: 64-79.

COSTA, S. H. \& PINTO, C. S., 1989. Os Efeitos Demográficos da Contracepção - a Queda da Fecundidade. Quando a Paciente é Mulher. Braslia, DF: CNDM.

DELGADO, M. B. G. \& LOPES, M. M., 1992. Mulheres trabalhadoras e meio ambiente: um olhar feminista no sindicalismo. Revista Estudos Feministas, Rio de Janeiro (CIEC/ECO/UFRJ), pp. 155-162.

DIEGUES, C. \& TOLIPAN, H., 1992. Censo apura que Brasil tem 146 milhões de habitantes. Jornal do Brasil, Rio de Janeiro, 1ํ Caderno, pág. 05, 06/02/92.

DONZELOT, J., 1980. A Polícia das Famílias. Rio de Janeiro: Graal.

DUMAIS, L., 1992. Impact of participation of women in science: on rethinking the place of women especially in occupational health. Women \& Health, 18: 11-25.

ESTRYN-BEHAR, M. \& POINSIGNON, H., 1989. Travailler à l'Hôpital. Paris: Berger-Levrault.

GRAY-TOFT, P. \& ANDERSON, J. G., 1981. Stress among hospital nursing taff: its causes and effects. Social Science \& Medicine, 15A: 639-647. 
IBGE (Instituto Brasileiro de Geografia e Estatística), 1992. Anuário Estatístico do Brasil: 1992. Vol. 52, Rio de Janeiro: IBGE.

KERGOAT, D.,1978. Onvrier=Ouvrières? Propositions pour une articulation theorique de deux variables: sexe et classe sociale. Critiques de l'Économie Politique, Paris, (5) oct/déc: 65-98. (nouvelle serie)

1990. Qualification et rapports sociaux de sexe: le cas des ouvrières et celui des infirmières. In: Les Infirmières et Leur Coordination (D. Kergoat, F. Imbert, H. Lê Doiré \& Senotier, eds), pp. 56-66, Paris: Editions Lamarre.

KRIEGER, N. \& FEE, E., 1994. Man-made medicine and women's health: the biopolitics of sex/gender and race/ethnicity. International Journal of Health Services, 24: 265-283.

LA ROSA, J. H., 1988. Women, work and health: employment as a risk factor for coronary disease. American Journal of Obstetrician, and Gynecology, 158: 1597-1602.

LAVINAS, L. \& CASTRO, M. G., 1990. Do Femi-nino ao Gênero: a Construção de um Objeto. Estudos sobre a Mulher no Brasil: Avaliação e Perspectivas. São Paulo: Fundação Carlos Chagas. (Mimeo.)

LEWIN, E. \& OLESEN, V., 1985. Occupational health and women: the case of clerical work. In: Women, Health and Healing: Toward a New Perspective (E. Lewin \& V. Olesen, eds), Chap. 3, pp. 53-86, New York, London: Tavistock Publications.

MACHADO, M. H., 1989. A mão de obra feminina no setor saúde no Brasil. In: Mulher, Saúde e Sociedade no Brasil (E. Labra, org), pp. 119134, Petrópolis: Vozes/Rio de Janeiro: Abrasco.

MACHADO-NETO, Z., 1987. A força de trabalho da mulher no espaço do bairro. Caderno do NEIM, Salvador, 4: 08-16.

MÉDICI, A. C., 1989. Mulher brasileira: muito prazer. In: Mulher, Saúde e Sociedade no Brasil (E. Labra, org), pp. 71-118, Petrópolis: Vozes/ Rio de Janeiro: Abrasco.

MEIJERS, J. M. M.; SWAEN, G. M. H.; VOLOVICS, A.; LUCAS, L. J. \& VLIET, K. V., 1989. Ocupational cohort studies: the influence of design characteristics on the Healthy Worker Effect. International Journal of Epidemiology, 18: 970-975.

MESSING, K., 1992. Introduction: research directed to improving women's occupational health. Women \& Health, 18: 01-09.

MS (Ministério da Saúde)/SNAS/INCA (Instituto Nacional do Câncer)/PRO-ONCO,1993. Controle do Câncer: uma Proposta de Integração Ensino-Serviço. $2^{\mathrm{a}}$ ed., Rio de Janeiro: Pro-Onco.
MORGAN, S. L. \& DAVIS, R., 1989. Occupational hazards: nursing service personel. Professional Safety, 34: 09-11.

NASH, J., 1985. A decade of research on women in Latin America. In: Women and Change in Latin America (J. Nash \& H. Safa, coords), pp. 03-21, Philadelphia: Bergin \& Carvey.

NATHANSON, C. A., 1977. Sex, illness and medical care. A review of data, theory and method. Social Science \& Medicine, 11: 13-25.

NUNES, S. A., 1991. A medicina social e a questão feminina. Physis: Revista de Saúde Coletiva, 1: 49-76.

OIT (Organización Internacional del Trabajo), 1990. Conferencia Internacional del Trabajo. El Trabajo Nocturno. 77aㅗ Reunión. Ginebra: Organización Internacional del Trabajo. (Mimeo.)

OWEN, B. D., 1989. The magnitude of low back problem in nursing. Western Journal of Nursing Research, 11: 234-242.

PARKES, K. R., 1980. Occupational stress among student nurses -1 . A comparison of medical and surgical wards. Nursing Times, 76: 113-116.

PENA, M. V. J., 1981. Mulheres e Trabalhadoras: Presença Feminina na Constituição do Sistema Fabril. Rio de Janeiro: Paz Terra.

PITTA, A., 1991. Hospital, Dor e Morte como “Ofício". $2^{\underline{a}}$ ed, São Paulo: Hucitec.

POSSO, M. B. S., 1988. As Fontes Potenciais de Riscos Físicos e Químicos sobre os Membros da Equipe Cirúrgica. Tese de Doutorado, São Paulo: Escola de Enfermagem, Universidade de São Paulo.

RADIS/DADOS, 1986. A mulher brasileira: estatísticas de saúde. Volume 4, número 10, pp. 01-24.

RATTNER, D., 1993. The Second Sex at Work or a Tentative Agenda for Research in Women's Occupational Health. Chapel Hill, University of North California (Course of Epidemiology Occupational Health). (Mimeo.)

RUTENFRANZ, J.; KNAUTH, P. \& FISCHER, F. M., 1989. Trabalho em Turnos e Noturno. São Paulo: Hucitec.

SAFA, H., 1987. Women and change in Latin America. Inaugural Lecture. Utrecht, Faculty of Social Sciences, University of Utrecht. (Mimeo.)

SIMÕES, C. C. S. \& OLIVEIRA, L. A. P., 1988. Perfil Estatístico das Crianças e Mães no Brasil: a Situação de Fecundidade; Determinantes Gerais e Características da Transição Recente. Rio de Janeiro: Departamento de Estatísticas e Indicadores Sociais, IBGE.

SORENSEN, G. \& VERBRUGGE, L. M., 1987. Women, work and health. Annual Review of Public Health, 8: 235-251. 
SOUZA-LOBO, E., 1991. A Classe Operária tem Dois Sexos: Trabalho, Dominação e Resistência. São Paulo: Brasiliense/Secretaria Municipal de Cultura-SP.

THIERNEY, D.; ROMITO, P. \& MESSING, K., 1990. She ate not the bread of the idleness: exaustion is related to domestic and salaried working conditions among 539 Québec Hospital Workers. Women and Health, 16: 21-42.

TOLIPAN, H., 1992. Censo 91 faz prever que o Brasil do ano 2000 será menor. Jornal do Brasil, Rio de Janeiro, $1^{\circ}$ caderno, pág. 09,9 de fevereiro.

TOPF, M., 1988. Noise-induced occupacional stress and health in critical care nurses. Hospital Topics, 66: 30-34.

TRIOLO, P. K., 1989a. Occupational health hazards of hospital staff nurses (Part I). American Association of Occupational Health Nurses Journal, 37: 232-237.

TRIOLO, P. K., 1989b. Occupational health harzards of hospital staff nurses (Part II). American Association of Occupational Health Nurses Journal, 37: 274-279.
VALDES, T. \& GOMARIZ, E. (Coords), 1993. Mulheres Latinoamericanas em Dados: Brasil. Santiago do Chile: Instituto de la Mujer, Ministerio de Asuntos Sociales, FLACSO.

VALTORTA, A.; SIDI, E. \& BIANCHI, S. C. L., 1985. Estudo do absenteísmo médico num hospital geral de grande porte. Revista Brasileira de Saúde Ocupacional, 13: 55-61.

WALDRON, I., 1983. Employment and women's health: an analysis of causal relationships. In: Women and Health: the Politics of Sex in Medicine (E. Fee, ed), Chap. 6, pp. 119-138, New York: Baywood Publishing Company, Inc. (Policy, Politics, Health and Medicine Series, 4)

WINGARD, D. L., 1984. The sex differential in morbidity, mortality and lifestyle. Annual Review of Public Health, 5: 433-45. 